Check for updates

Cite this: RSC Adv., 2017, 7, 23157

\title{
A comparative degradation study of commercial lithium-ion cells under low-temperature cycling
}

\author{
Yakun Zhang, (DD ${ }^{a} \mathrm{Hao} \mathrm{Ge}^{a}{ }^{a}$ Jun Huang, ${ }^{a}$ Zhe Li ${ }^{\star a b}$ and Jianbo Zhang ${ }^{\star a b}$
}

Severe deterioration of lithium-ion cells at low temperatures constitutes one of the bottlenecks for the wide adoption of electric vehicles. Notwithstanding the remarkable progress in fundamental understanding, a knowledge gap remains in how the low-temperature aging depends on the material chemistry, the application orientation that is mainly dictated by electrode structure, and the cell format. In this contribution, four types of lithium-ion cells that are different in application orientation (power or energy), cathode chemistry $\left(\mathrm{LiNi}_{x} \mathrm{Mn}_{y} \mathrm{CO}_{1-x-y} \mathrm{O}_{2}\right.$ or $\left.\mathrm{LiNi}_{x} \mathrm{Co}_{y} \mathrm{Al}_{1-x-y} \mathrm{O}_{2}\right)$, and cell format (18 650 cell or pouch cell) are subjected to low-temperature cycling tests. The aging phenomena and mechanisms during lowtemperature cycling are systematically analyzed using electrochemical methods. Cell resistance increases more remarkably for energy-type cells, while cell capacity decreases more quickly for power-type cells during low-temperature cycling. Different material chemistries lead to different limiting processes during low-temperature cycling. Generated heat dissipates much more easily for pouch cells than for 18650 cells, thereby making lithium plating more serious for pouch cells during low-temperature cycling.

Received 2nd March 2017 Accepted 17th April 2017

DOI: 10.1039/c7ra02581e

rsc.li/rsc-advances
Waldmann et al. revealed the temperature dependence of the aging mechanism in LICs. The aging rate as a function of temperature follows an Arrhenius relation in the lowtemperature range of -20 to $25{ }^{\circ} \mathrm{C}$ and high-temperature range of $25-70{ }^{\circ} \mathrm{C}$, respectively. However, the variation trend of aging rate with temperature was opposite for the low- and high-temperature ranges. In the low-temperature range, the aging rate increased with decreasing temperature, which was attributed to lithium plating at the anode by using electrochemical methods and post-mortem analysis. ${ }^{10}$ A subsequent study developed a non-destructive method, that is, differential voltage/capacity analysis, to detect lithium plating during low-temperature cycling. ${ }^{\mathbf{1 1}}$ Moreover, thermal characterization of fresh and cycled cells showed that lithium plating leads to a significant increase of heat generation rate during thermal runaway and thus to a higher safety hazard. ${ }^{\mathbf{1 2}}$ The effects of charging parameters on mitigating lithium plating during low-temperature charging were examined in ref. 13. These research studies are limited to a specific type of LIC. It remains unclear how the observed aging phenomena and deduced aging mechanisms depend on the cell chemistry, format and size. This is the main objective of the present study. In this study, the aging phenomena and degradation mechanisms of four kinds of automotive LICs during low-temperature cycling were investigated. The cells are different in application orientation (power or energy), cathode chemistry $\left(\mathrm{LiNi}_{x} \mathrm{Mn}_{y} \mathrm{Co}_{(1-x-y)} \mathrm{O}_{2}\right.$ or $\left.\operatorname{LiNi}_{x} \mathrm{Co}_{y} \mathrm{Al}_{(1-x-y)} \mathrm{O}_{2}\right)$ and cell format (18 650 cell or pouch cell). The resistance-capacity plot was proposed as an identification tool for the lithium plating.
${ }^{a}$ State Key Laboratory of Automotive Safety and Energy, Tsinghua University, Beijing 100084, China.E-mail: zhe_li@tsinghua.edu.cn; jbzhang@tsinghua.edu.cn

${ }^{b} B e i j i n g$ Co-innovation Center for Electric Vehicles, Beijing Institute of Technology, Beijing 100081, China 


\section{Experiment}

\section{Cell information}

Four kinds of commercial LICs were subjected to the lowtemperature degradation test. The key parameters of these four kinds of cells are shown in Table 1. The LICs are different in application orientation, material chemistry, nominal capacities and format. For convenience, the four kinds of LICs are labelled as cell A, B, C, and D, respectively. For reproducibility considerations, three samples of each kind of cell were tested. All tested cells were placed into one temperature chamber (GDJW-225, Yashilin, China) for temperature control, and the surface temperature of the cells was recorded during the experiment. The cells were charged or discharged using a Maccor Series 4000 system (Maccor Inc., USA).

\section{Experiment protocol}

A reference performance test (RPT) test was designed during the cycling to characterize the degradation process at several designated points. Hence, the degradation experiment includes two parts, namely, the low-temperature cycling test (Fig. 1) and the RPT (Table 2). The low-temperature cycling test was conducted at $-10{ }^{\circ} \mathrm{C}$ using protocols recommended by manufacturers. Constant current-constant voltage (CC-CV) charging method was used; that is, the cell was charged under constant current at SC current until the cell voltage reached the predesignated cutoff voltage, and then the cell was charged under constant voltage until the charging current fell below $1 / 10^{\text {th }}$ of the SC current. Then, the cell was discharged under constant current at SD current. No rest period was placed between charging and discharging processes, while each charging-discharging cycle was followed by a rest period of $1 \mathrm{~h}$. The lowtemperature cycling test was terminated when the cell capacitance fell below $70 \%$ of the fresh capacity.

RPT was conducted repeatedly every 20 low-temperature cycles. RPT consists of a capacity test and a direct-current resistance test, as shown in Table 2 . Two capacity values can be derived from RPT. One is the residual capacity of the lowtemperature cycling (designated as $\operatorname{Res} C_{\mathrm{LT}}$ ) obtained from the first discharging process in the RPT, representing the capacity that cannot be further discharged at $-10^{\circ} \mathrm{C}$ but can be drawn

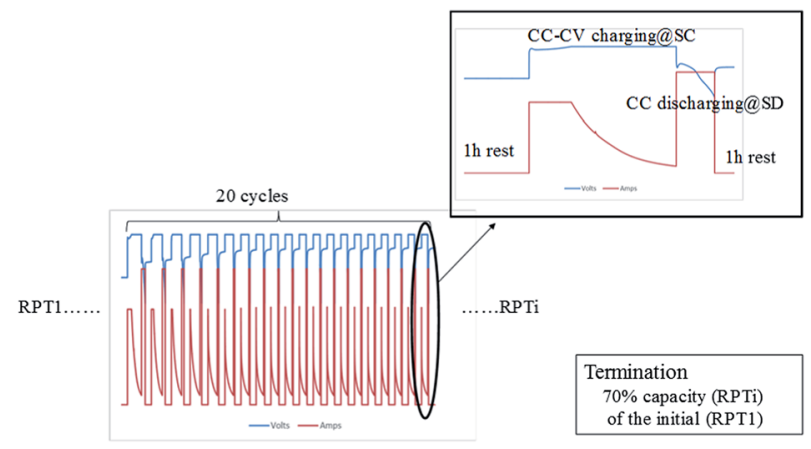

Fig. 1 Protocol for the low-temperature cycling test.

Table 2 RPT protocol at $25^{\circ} \mathrm{C}$

Protocol at $25{ }^{\circ} \mathrm{C} \quad$ Quantity

Rest for $1 \mathrm{~h}$ to ensure that temperature reaches equilibrium

Discharge at SD current to the cutoff voltage

Residual capacity $\left(\operatorname{Res} C_{\mathrm{LT}}\right)$

Rest for $1 \mathrm{~h}$

Charge the cell using CC-CV method

Rest for $1 \mathrm{~h}$

Discharge at SD current to the cutoff voltage

Remaining useful capacity $\left(\operatorname{Rem} C_{\mathrm{RT}}\right)$

Rest for $1 \mathrm{~h}$

Charge the cell using CC-CV method

Rest for $1 \mathrm{~h}$

Discharge the cell intermittently at SD current Direct current resistance $\left(R_{\mathrm{DC}}\right)$

from the cell at $25{ }^{\circ} \mathrm{C}$. The other one is the remaining useful capacity of the cell at room temperature $\left(\mathrm{Rem} C_{\mathrm{RT}}\right)$, calculated from the second discharging process in the RPT, which is used to characterize the degradation degree of the cell. The direct current resistance was calculated according to $R_{\mathrm{SOC}}=\frac{V-V^{\prime}}{I}$, where $V$ is the voltage value before discharging at a specific SOC, $V^{\prime}$ the voltage after discharging for 60 seconds, and $I$ the discharging current. The direct current resistance at 50\% SOC was chosen as the representative resistance in subsequent analysis.

Table 1 Key parameters of the sample cells

\begin{tabular}{|c|c|c|c|c|}
\hline Image and format & $+\times$ 泪 & in: & & $\square$ \\
\hline Chemistry & $\begin{array}{l}\mathrm{LiNi}_{x} \mathrm{Mn}_{y} \mathrm{Co}_{(1-x-y)} \mathrm{O}_{2}(\mathrm{NMC}) / \\
\text { graphite }\end{array}$ & $\begin{array}{l}\operatorname{LiNi}_{x} \mathrm{Co}_{y} \mathrm{Al}_{(1-x-y)} \mathrm{O}_{2}(\mathrm{NCA}) / \\
\text { graphite }\end{array}$ & NCM/graphite & NCM/graphite \\
\hline Type & Energy & Energy & Power & Power \\
\hline Lower limit voltage & $2.5 \mathrm{~V}$ & $2.5 \mathrm{~V}$ & $2.75 \mathrm{~V}$ & $2.75 \mathrm{~V}$ \\
\hline Standard charging (SC) current & $0.3 \mathrm{C}$ & $0.7 \mathrm{C}$ & $1 \mathrm{C}$ & $1 \mathrm{C}$ \\
\hline Standard discharging (SD) current & $0.3 \mathrm{C}$ & $1 \mathrm{C}$ & $1 \mathrm{C}$ & $1 \mathrm{C}$ \\
\hline
\end{tabular}




\section{Results and discussion}

\section{Degradation}

Fig. 2 shows the capacity retention calculated from the remaining useful capacity for the tested cells. The capacity values are normalized with respect to the respective initial values for comparison. Fig. 2(a) shows that the $\operatorname{Rem} C_{\mathrm{RT}}$ decreases sharply in the aging process for all cells, and the degradation rate follows the order of $\mathrm{A}>\mathrm{C}>\mathrm{D}>\mathrm{B}$. Usually, cell lifetime is defined as the point at which the cell capacity fades to $80 \%$ of its initial value. Cell B, with NCM as cathode material, has a much longer lifetime than other cells under this lowtemperature condition. This large lifetime difference among the cells is unexpected because the cells have similar chemistry, i.e. ternary material based on $\mathrm{LiNiO}_{2}$ at cathode and graphite at anode. The major cause, as discussed in SOC window section, is that the depth of discharge (DOD) for the four kinds of cells are different.

To compensate for this difference, an effective cycle number considering the capacity throughput during low-temperature cycling is defined as $n_{\mathrm{eff}}=n \sum_{1}^{n} C_{\mathrm{LT}} / \sum_{1}^{n} C_{\mathrm{RT}}$, where $n_{\mathrm{eff}}$ is the effective cycle number, $n$ the cycle number, $C_{\mathrm{LT}}$ the charging and discharging capacity (Ah-throughput) for one cycle at low temperature, and $C_{\mathrm{RT}}$ the Ah-throughput for one cycle at room temperature. Since the lifetime of a cell is usually more than one thousand cycles, $C_{\mathrm{RT}}$ is treated as a constant, namely, the nominal capacity given by the manufacturer, for each cell within dozens of cycles. The effective cycle number better
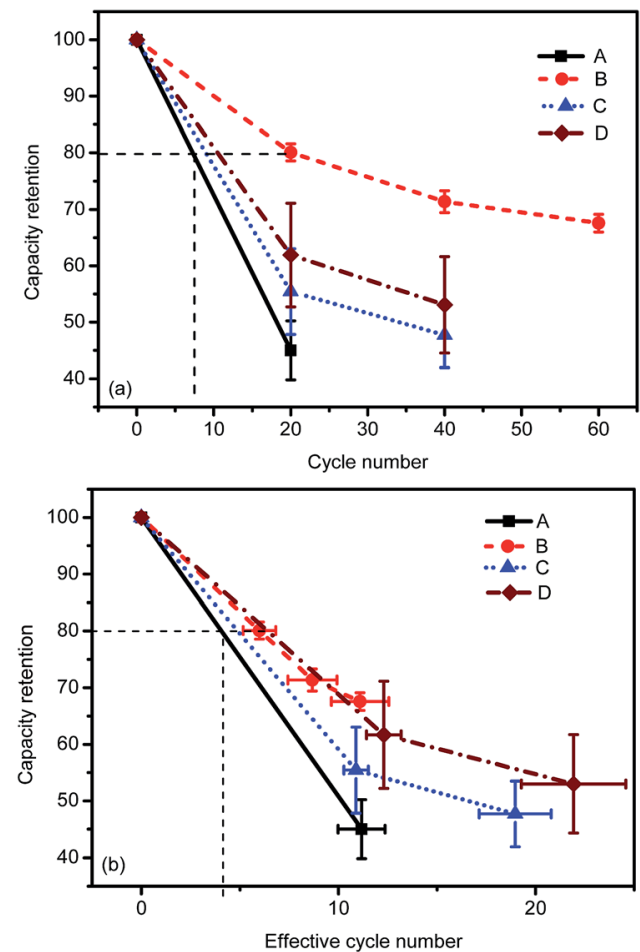

Fig. 2 Rem $C_{R T}$ retention as a function of cycle number (a) and effective cycle number (b). illustrates the actual Ah-throughput of cell during cycling. Fig. 2(b) shows the $\operatorname{Rem} C_{\mathrm{RT}}$ retention as a function of $n_{\mathrm{eff}}$. Fig. 2(b) indicates that the cycling lifetimes of the cells at low temperature are similar on the scale of $n_{\text {eff }}$.

Cell resistance increases concomitantly when the cell capacity decreases during degradation. Hence, both cell resistance and cell capacity can be used to evaluate the degradation rate. Fig. 3(a) shows that the DC resistance at 50\% SOC increases with the cycle number, in the same sequence as in Fig. 2(a). However, the increasing rates of DC resistance on the scale of $n_{\text {eff }}$ are different from the capacity results in Fig. 2(b). DC resistance of energy-type cells (cell A and B) increases more significantly than that of the power-type cells (cell C and D) on the scale of $n_{\text {eff }}$. Besides, the cell-to-cell uniformity deteriorates with cell degradation. The error bars in Fig. 2 and 3 indicate that cell $\mathrm{B}$ retains the best uniformity during the low-temperature aging process.

The $R-Q$ plot, that is, DC resistance at SOC $=50 \%$ versus the Rem $C_{\mathrm{RT}}$, is useful in analyzing aging mechanisms. ${ }^{\mathbf{1 4}}$ Fig. 4 clearly shows that the $R-Q$ plot falls into two regimes according to the cell type. For energy-type cells A and B, the DC resistance increases more remarkably than the capacity decrease during the degradation process. Meanwhile, for the power-type cells $\mathrm{C}$ and $\mathrm{D}$, the capacity decrease is more intensified than the resistance increase.

\section{Residual capacity}

The $\operatorname{Res} C_{\mathrm{LT}}$ from RPT helps us to understand the limiting processes during low-temperature cycling. Fig. 5 shows the
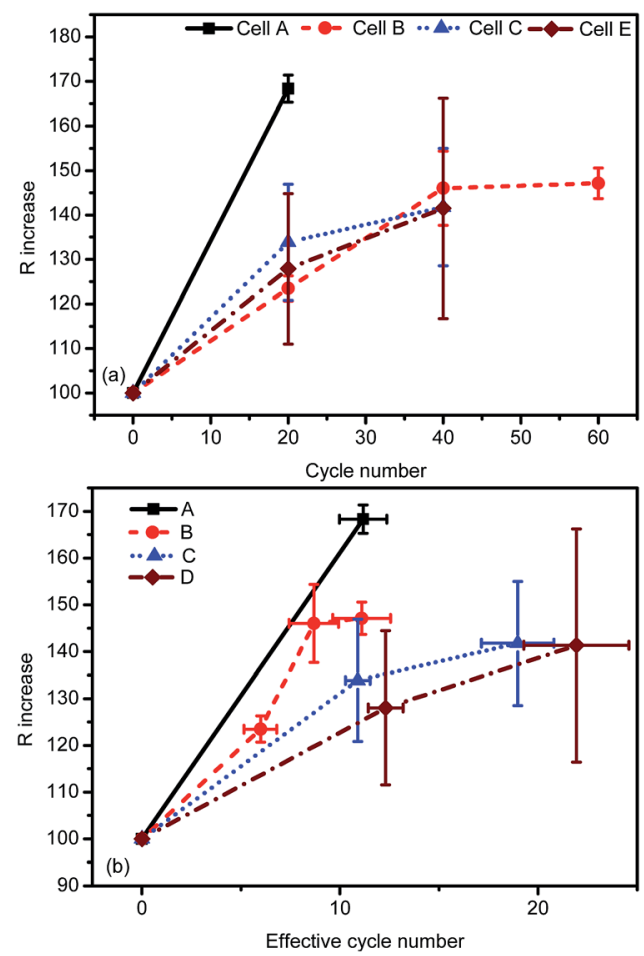

Fig. 3 DC resistance at 50\% SOC as a function of cycle number (a) and effective cycle number (b). 


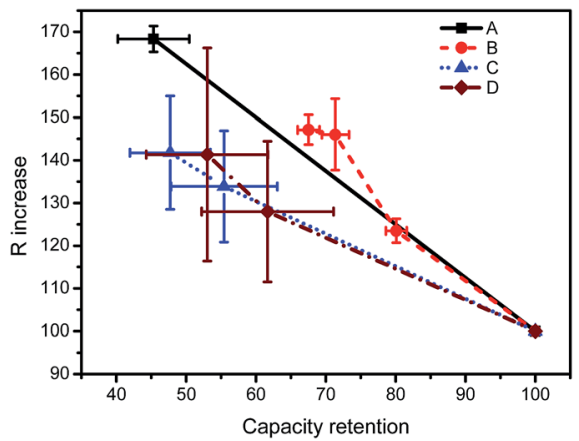

Fig. $4 R-Q$ plot: $D C$ resistance at SOC $=50 \%$ versus the RemC $C_{R T}$.

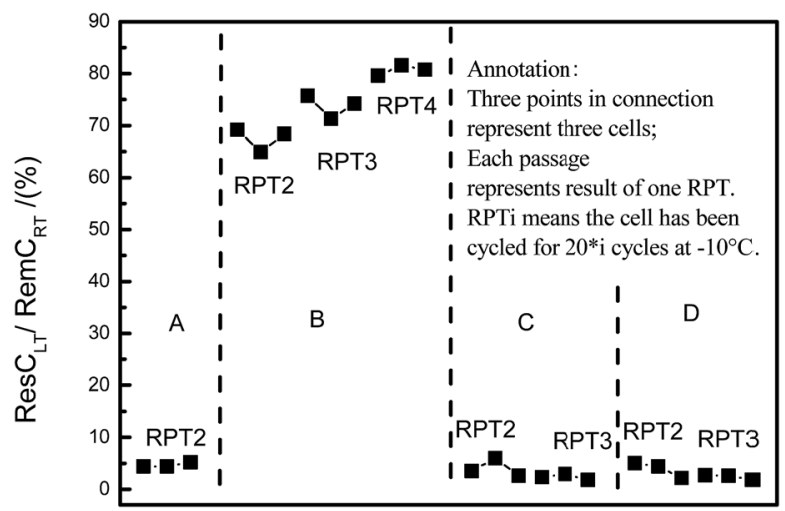

Fig. 5 Proportion of $\operatorname{Res} C_{\mathrm{LT}}$ to $\operatorname{Rem} C_{\mathrm{RT}}$.

proportion of the $\operatorname{Res} C_{\mathrm{LT}}$ to the $\operatorname{Rem} C_{\mathrm{RT}}$, termed as the normalized $\operatorname{Res} C_{\mathrm{LT}}$, of all cells during low-temperature cycling degradation. It can be seen in Fig. 5 that the normalized $\operatorname{Res} C_{\mathrm{LT}}$ follows a sequence: $\mathrm{B} \gg \mathrm{A} \approx \mathrm{C} \approx \mathrm{D}$. To be specific, the normalized $\operatorname{Res} C_{\mathrm{LT}}$ of cells $\mathrm{A}, \mathrm{C}$ and $\mathrm{D}$ is about $3 \%$, implying that these cells could be discharged almost completely at $-10{ }^{\circ} \mathrm{C}$. The normalized $\operatorname{Res} C_{\mathrm{LT}}$ of the cell B is about $69 \%$ after 20 cycles at $-10{ }^{\circ} \mathrm{C}$ and increases to $80 \%$ with increasing cycle number. This suggests that cell $\mathrm{B}$ can hardly be discharged completely at $-10{ }^{\circ} \mathrm{C}$. Hence, cell $\mathrm{B}$, with NCA as cathode material, was cycled within a narrow SOC window due to the 'early death' during discharging. In other words, the limiting process for cell $\mathrm{B}$ under low-temperature cycling is the discharging process, not the widely accepted charging process. For the other three kinds of cells with NCM as cathode, they can be discharged almost completely at $-10{ }^{\circ} \mathrm{C}$. However, the capacity of these cells at $-10{ }^{\circ} \mathrm{C}$ is much lower than at $25^{\circ} \mathrm{C}$. As a result, we conclude that the limiting process for these cells under lowtemperature cycling is the charging process, as widely believed for LICs. ${ }^{15}$

\section{SOC window}

The SOC window within which the cells are cycled at $-10{ }^{\circ} \mathrm{C}$ is important to understanding the degradation. Fig. 6 illustrates how to calculate the SOC window during low-temperature cycling. In the subsequent calculation, a basic approximation

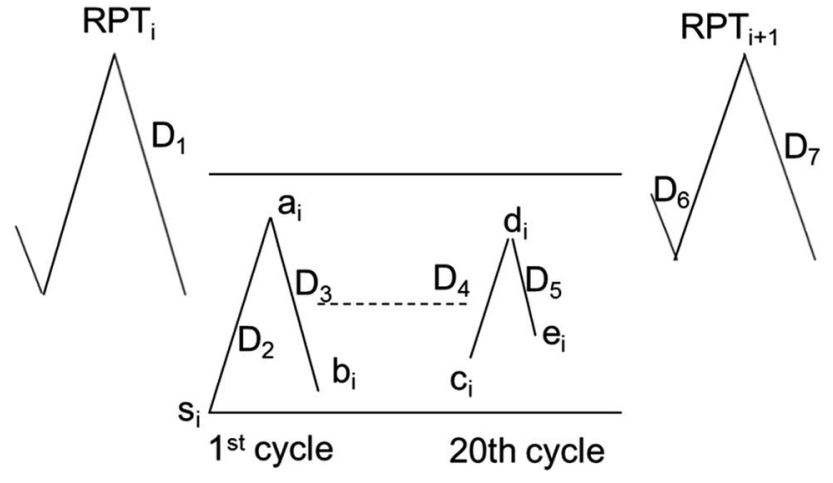

Fig. 6 Illustration of SOC window calculation process.

says that the inherent capacity, that is, the theoretical capacity that can be ideally drawn from or stored in the cell, is the same for the RPT and the first low-temperature cycle before/after the RPT. This inherent capacity is approximated by the $\operatorname{Rem} C_{\mathrm{RT}}$ measured during RPT and used in the SOC calculation.

The initial SOC of the $1^{\text {st }}$ cycle of the low-temperature cycling test just after the RPT, $s_{\mathrm{i}}$, is set as zero because the cell is completely discharged in RPT. Using $s_{\mathrm{i}}$ as a reference point, we calculate the SOC at the end of the $1^{\text {st }}$ charging of the lowtemperature cycling test, $a_{\mathrm{i}}$, according to:

$$
a_{i}=s_{i}+\frac{D_{2}}{D_{1}},
$$

where $D_{1}$ is the Rem $C_{\mathrm{RT}}$ in $\mathrm{RPT}_{\mathrm{i}}$ and $D_{2}$ the charging capacity of the $1^{\text {st }}$ charging of low-temperature cycling test. Then, the SOC at the end of the following discharging process, $b_{\mathrm{i}}$, is:

$$
b_{i}=a_{i}-\frac{D_{3}}{D_{1}}
$$

with $D_{3}$ being the discharging capacity of the subsequent discharging process.

Similarly, the SOC at the end of the discharging process of the $20^{\text {th }}$ cycle can be calculated using $\operatorname{Res} C_{\mathrm{LT}}$ and $\operatorname{Rem} C_{\mathrm{RT}}$ from the subsequent RPT, according to:

$$
e_{i}=\frac{D_{6}}{D_{7}}
$$

where $D_{6}$ is the $\operatorname{Res} C_{\mathrm{LT}}$ and $D_{7}$ is the remaining capacity at $\mathrm{RPT}_{i+1}$. Then, we can trace back to calculate the SOC at the beginning of the $20^{\text {th }}$ discharging process, that is, the end of the $19^{\text {th }}$ charging process, according to:

$$
d_{i}=e_{i}+\frac{D_{5}}{D_{7}}
$$

where $D_{5}$ is the capacity of the $20^{\text {th }}$ discharging process. Finally, the SOC at the beginning of the $19^{\text {th }}$ charging process is given by:

$$
c_{i}=d_{i}-\frac{D_{4}}{D_{7}}
$$

where $D_{4}$ is the capacity of the $19^{\text {th }}$ charging process.

The SOC windows are shown in Fig. 7 for charging and Fig. 8 for discharging. The 18650 cell with NCA as cathode material 


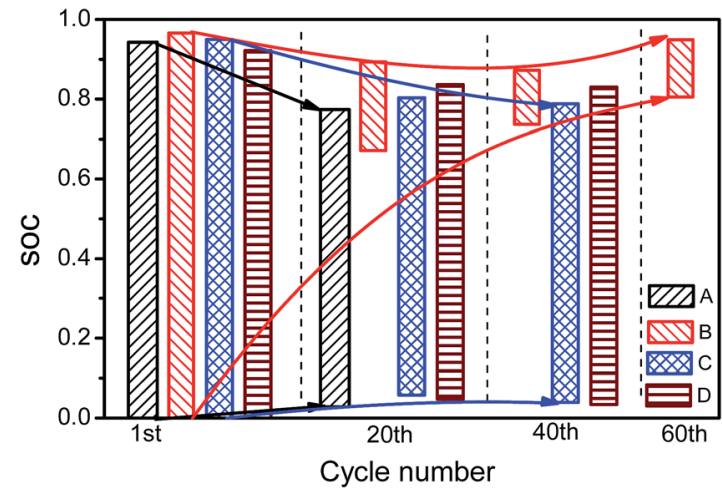

Fig. 7 SOC window during low-temperature charging.

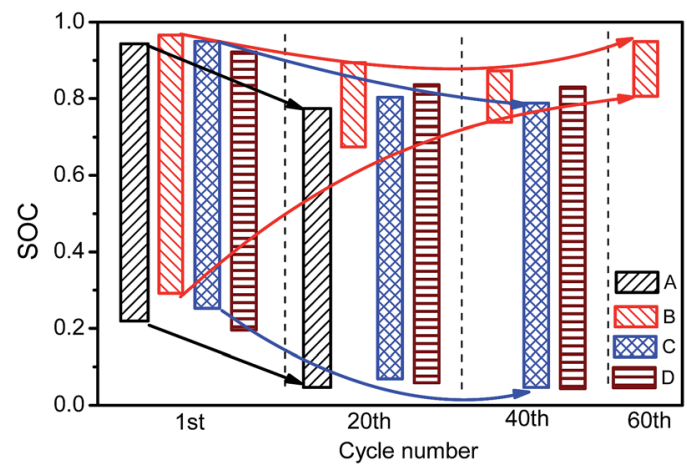

Fig. 8 SOC window during low-temperature discharging.

(cell B) has a sharper narrowing of the SOC window, compared with cells with NCM as cathode material in package format (cell $\mathrm{A}, \mathrm{C}$ and $\mathrm{D}$ ). For the $1^{\text {st }}$ charging process, the SOC windows are $0-95 \%$ for all the cells. With low-temperature cycling, the SOC at the beginning of charging increases while the SOC at the end of charging decreases, leading to narrowed SOC windows and smaller charging capacities. For cells A, C and D, the SOC at the beginning of charging increases gradually. In contrast, the SOC at the beginning of charging of cell $\mathrm{B}$ grows much higher than the other cells. The SOC at the end of charging of cells A, C and $\mathrm{D}$ decreases more significantly than that of cell $\mathrm{B}$, implying that the limiting process under low-temperature cycling for cells A, C and $\mathrm{D}$ is charging, in which lithium plating is probably involved. In terms of the pouch cells, generated heat dissipates much more easily than the 18650 cells. As a result, the temperature increase is smaller as compared with the 18650 cells, making lithium plating more serious for pouch cells at low-temperature cycling.

Fig. 8 shows the SOC window during the discharging process. For the $1^{\text {st }}$ discharging process, the difference in SOC window among the four kinds of cells is not significant. With low-temperature cycling, the SOC at the beginning of discharging decreases. Among the four kinds of cells, cells with NCM as cathode material decrease most significantly. The SOC at the end of discharging exhibits a remarkable difference between the NCM cells (cells A, C and D) and NCA cells (cell B).
For cells A, C and D, the SOC at the end of discharging decreases synchronously with the starting SOC point, resulting in a slightly changed SOC window length. For cell B, the SOC at the end of discharging rapidly increases with cycling. The SOC window is located in the high SOC region, representing markedly reduced discharge capacity, which is mainly caused by the large kinetic overpotential of cell B in 18650 format, Fig. 12(b).

\section{$R-Q$ plot}

A $R-Q$ plot is drawn for the first 20 low-temperature cycles in Fig. 9. The resistance $(R)$ is calculated at the beginning of discharging. The discharging capacity decreases during the lowtemperature cycling for all cells, but $R$ decreases first and then increases quickly. As is well known, the $R$ of a cell is affected by temperature, SOC and the degradation state. To clarify the reason why $R$ decreases first, these three factors are analyzed one by one as follows.

Fig. 10 shows the temperature variation curves during the first few low-temperature cycles. Cell B, with the 18650 format, exhibits the largest temperature variation due to the large heat generation rate as a consequence of the large overpotential and the small heat dissipation rate. For all cells, the temperature at the beginning of discharging returns to the preset value in the range between $-9{ }^{\circ} \mathrm{C}$ to $-10{ }^{\circ} \mathrm{C}$. Therefore, the temperature influence on DC resistance is minor.

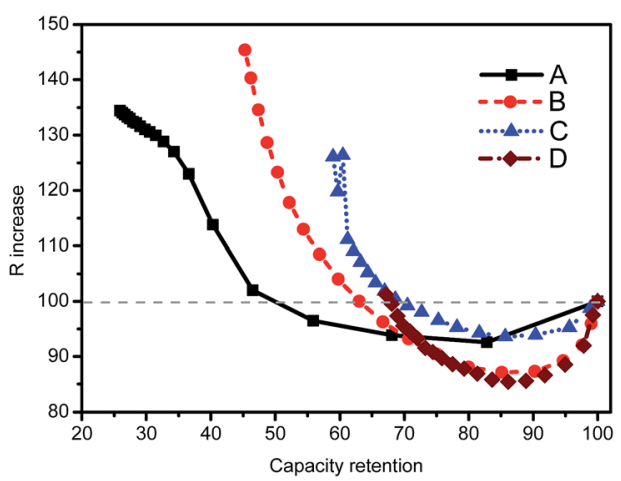

Fig. 9 Resistance at the starting SOC of discharging versus capacity during the first 20 cycles.

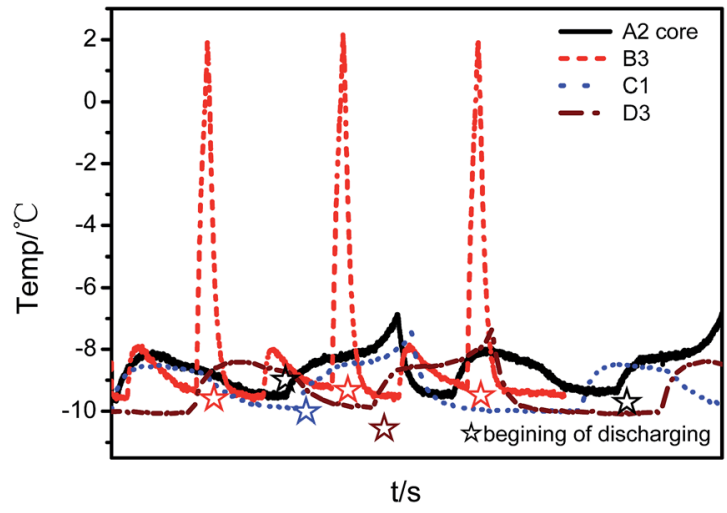

Fig. 10 Temperature variation during the first 20 cycles 
The SOC at the beginning of discharging can be known from Fig. 8, which is in the range of $77-97 \%, 87-96 \%, 78-95 \%, 83-$ $93 \%$ for cells A, B, C and D, respectively. To compensate the capacity difference, a normalized resistance $\left(R_{\text {norm }}\right)$ is defined as the product of the DC resistance and the capacity. $R_{\text {norm }}$ at different SOCs are calculated at room temperature. Relative values of $R_{\text {norm }}$ at $70-100 \%$ SOC, normalized using the value at $100 \%$ SOC as a reference, are employed to characterize the sensitivity of $R_{\text {norm }}$ to SOC variations. Fig. 11(a) shows the $R_{\text {norm }}$ of four kinds of cells at different SOCs, and Fig. 11(b) shows the sensitivity of $R_{\text {norm }}$ to SOC variations at room temperature. $R_{\text {norm }}$ changes within $10 \%$ when the SOC changes from $70 \%$ to $100 \%$ for all examined cells. As a result, the variation in SOC at the beginning of discharging (namely, the end of charging) cannot account for the $R$ variation in Fig. 9. In addition, $R_{\text {norm }}$ of cell $\mathrm{B}$ is much higher than that of the other three cells, which induces incomplete discharging.

It is reported that micro-cracking and lithium plating can reduce the resistance. ${ }^{16}$ In this case, we tentatively postulate that lithium plating decreases $R$ in Fig. 9, as discussed in the following section.

\section{Lithium plating and stripping}

From the above discussions, it could be speculated that graphite anode experiences lithium plating under the $\mathrm{CC}-\mathrm{CV}$ charging protocol at low temperatures. It is reported that lithium stripping will lead to a platform in the discharging curves. ${ }^{5}$ As a result, the discharging curves can be used to verify the assumption of lithium plating. Charging and discharging
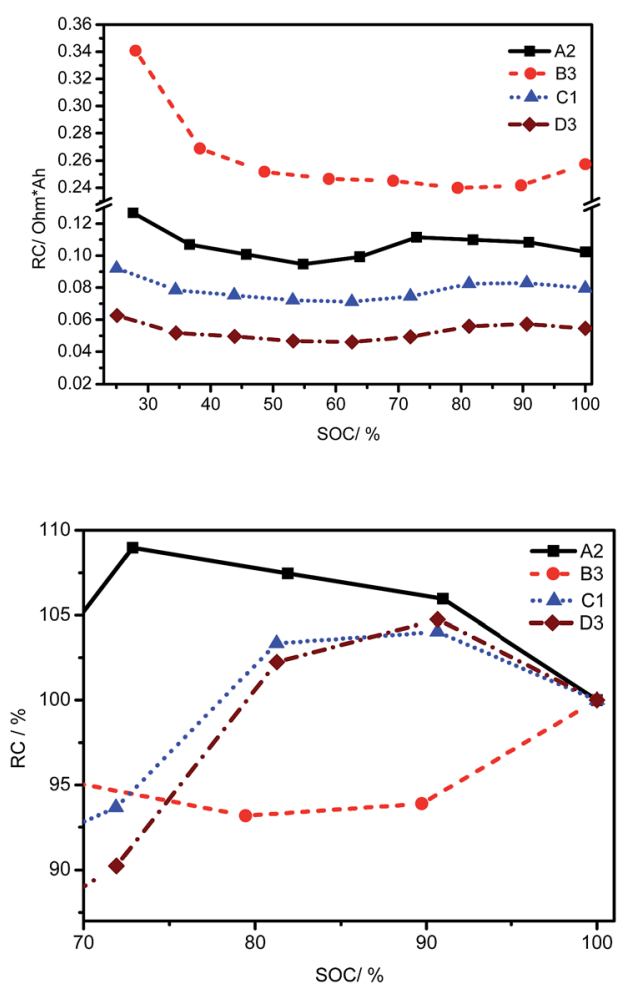

Fig. $11 R_{\text {norm }}$ as a function of SOC and the normalized value relative to $R_{\text {norm }}$ at $100 \%$ SOC.
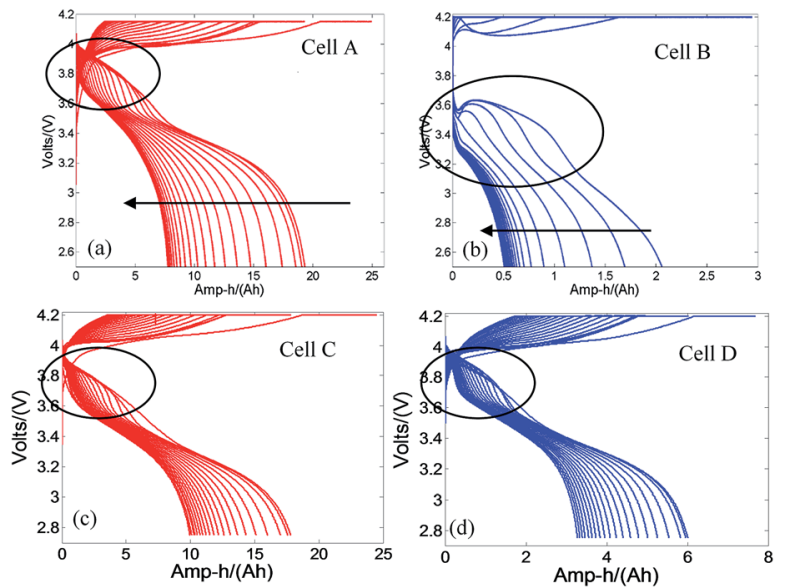

Fig. 12 Charging and discharging curves for the 20 cycles in the $1^{\text {st }}$ cycling.

curves for the first 20 cycles at $-10{ }^{\circ} \mathrm{C}$ are shown in Fig. 12 . Platforms in discharging curves are observed for all types of cells during the first several cycles, indicating lithium plating on graphite anode material during the charging process at $-10{ }^{\circ} \mathrm{C}^{\mathbf{8}}$

In detail, the platforms of cell $\mathrm{B}$ are different from that of cells A, C and D. Cells A, C and D show platforms at the beginning of discharging, whereas the platform manifests at a lower voltage and shows a sign of voltage rebound for cell B. The lower cell voltage during discharging for cell $\mathrm{B}$ is attributed to the greater cell overpotential, as evidenced by the larger temperature rise (Fig. 10) and the larger $R_{\text {norm }}$ (Fig. 11(a)). Moreover, the larger temperature rise also explains the voltage rebound..$^{17,18}$

\section{Conclusions}

This study compared the performance of four kinds of LICs during low-temperature cycling at $-10{ }^{\circ} \mathrm{C}$. These cells are different in application orientation (power or energy), cathode chemistry $\left(\mathrm{LiNi}_{x} \mathrm{Mn}_{y} \mathrm{Co}_{(1-x-y)} \mathrm{O}_{2}\right.$ or $\left.\operatorname{LiNi}_{x} \mathrm{Co}_{y} \mathrm{Al}_{(1-x-y)} \mathrm{O}_{2}\right)$, and cell format (18 650 cell or pouch cell). By virtue of electrochemical analysis, we found that:

- DC resistance increased more remarkably for energy-type cells $\mathrm{A}$ and $\mathrm{B}$, while the capacity decrease was more intensified for power-type cells $\mathrm{C}$ and $\mathrm{D}$.

- The limiting process under low-temperature cycling for cell B with NCA as the cathode material is the discharging process, not the widely accepted charging process. For the other three kinds of cells with NCM as cathode material, the limiting process under low-temperature cycling is the charging process.

- In terms of pouch cells (cells A, C and D), generated heat dissipates much more easily than the 18650 cells (cell B). As a result, the temperature increase in pouch cells is smaller as compared with the 18650 cells, making lithium plating more serious for pouch cells during low-temperature cycling.

- The appearance of lithium plating at the graphite anode during low-temperature cycling was speculated by the $R-Q$ plot and confirmed by platforms in the discharging curves. 


\section{Acknowledgements}

This work is supported by the National Natural Science Foundation of China under the grant number of 51377097 and 51577104, and China Postdoctoral Science Foundation funded the project with grant number 2014M560079.

\section{References}

1 A. Barré, B. Deguilhem, S. Grolleau, M. Gérard, F. Suard and D. Riu, J. Power Sources, 2013, 241, 680-689.

2 Y. Ji, Y. C. Zhang and C. Y. Wang, J. Electrochem. Soc., 2013, 160, A636-A649.

3 D. Burow, K. Sergeeva, S. Calles, K. Schorb, A. Börger, C. Roth and P. Heitjans, J. Power Sources, 2016, 307, 806-814.

4 T. C. Bach, S. F. Schuster, E. Fleder, J. Müller, M. J. Brand, H. Lorrmann, A. Jossen and G. Sextl, Journal of Energy Storage, 2016, 5, 212-223.

5 M. Petzl and M. A. Danzer, J. Power Sources, 2014, 254, 80-87. 6 S. Schindler, M. Bauer, M. Petzl and M. A. Danzer, J. Power Sources, 2016, 304, 170-180.

7 M. Zier, F. Scheiba, S. Oswald, J. Thomas, D. Goers, T. Scherer, M. Klose, H. Ehrenberg and J. Eckert, J. Power Sources, 2014, 266, 198-207.
8 A. Senyshyn, M. J. Mühlbauer, O. Dolotko and H. Ehrenberg, J. Power Sources, 2015, 282, 235-240.

9 M. C. Smart and B. V. Ratnakumar, J. Electrochem. Soc., 2011, 158, A379-A389.

10 T. Waldmann, M. Wilka, M. Kasper, M. Fleischhammer and M. Wohlfahrt-Mehrens, J. Power Sources, 2014, 262, 129-135.

11 M. Petzl, M. Kasper and M. A. Danzer, J. Power Sources, 2015, 275, 799-807.

12 M. Fleischhammer, T. Waldmann, G. Bisle, B.-I. Hogg and M. Wohlfahrt-Mehrens, J. Power Sources, 2015, 274, 432-439.

13 M. Ouyang, Z. Chu, L. Lu, J. Li, X. Han, X. Feng and G. Liu, J. Power Sources, 2015, 286, 309-320.

14 L. Su, J. Zhang, C. Wang, Y. Zhang, Z. Li, Y. Song, T. Jin and Z. Ma, Appl. Energy, 2016, 163, 201-210.

15 Z. Li, J. Huang, B. Y. Liaw, V. Metzler and J. B. Zhang, J. Power Sources, 2014, 254, 168-182.

16 J. Vetter, P. Novak, M. R. Wagner, C. Veit, K. C. Moller, J. O. Besenhard, M. Winter, M. Wohlfahrt-Mehrens, C. Vogler and A. Hammouche, J. Power Sources, 2005, 147, 269-281.

17 S. C. Chen, C. C. Wan and Y. Y. Wang, J. Power Sources, 2005, 140, 111-124.

18 W. Walker and H. Ardebili, J. Power Sources, 2014, 269, 486497. 